\title{
EFEITOS DA APLICAÇÃO DO BORO EM SOLOS SOB VEGETAÇÃO DE CERRADO
}

Carlos R. P. Laun* Moacyr 0. C. do Brasil Sobrinho** Toshio Igue ${ }^{\star \star \star}$

0 presente trabalho teve como objetivo estudar os efeitos da aplicação de boro em duas unidades de solo cobertas com vegetação de cerrado, classificadas cocomo, Latossolo Vermelho Amarelo-fase arenosa e Regossolo (Areas Quartzosas), que ocorrem no município de São Simão, no Estado de São Paulo.

Foram feitas determinações químicas de boro solúvel em amostras colhidas nas áreas experimentais antes e depois do tratamento dos solos com calagem.

As determinaçōes do boro foram comple-

* EMBRAPA, MA

** Departamento de Solos, Geologia e Fertilizantes, ESALQ/USP

$\star \star \star$ I.A.C. - Campinas 
mentados com testes biológicos do giras sol (Helianthus annuus L.).

Simultaneamente foram conduzidos ensaios de campo para estudos sobre a aplicação de doses crescentes de boro no feijoeiro (Phaseolus vulgaris L.).

As conclusões do trabalho foram as seguintes:

1 - 0 teste do girassol apresentou boa concordância com os testes químicos, in dicando que as duas unidades de solo são ligeiramente deficientes ou não deficientes em boro.

2- 0 solo classificado como Regossolo (Areias Quartzosas) mostrou-se mais ele vado em boro do que o Latossol Vermel ho Amarelo - fase arenosa.

3- Não houve efeito da aplicação de boro na produção do feijoeiro.

\section{NTRODUÇÃO}

A pobreza dos solos sob vegetação de cerrado tem sido constatada por inúmeros pesquisadores.

Ocupando aproximadamente $25 \%$ da área do território nacional, esses solos, formados a partir dos mais diferentes tipos de materiais, sob precipitação pluviométrica média de 1.000 a $1.500 \mathrm{~mm}$, apresentam uma topografia bastante favorável a mecanização agricola, repre s.ntando um dos maiores potenciais agro-silvo-pastoris do Pais, desde que se encontrem sol uções adequadas 
e econômicas para o seu aproveitamento racional.

No Estado de São Paulo, deficiências de boro tèm ocorrido em algumas culturas tais como algodoeiro, cafeeiro, citrus, eucaliptos, mamoeiro, Pinus e em hortaliças com maior frequência.

Os solos sob vegetação de cerrado, conforme o seu material de origem e os processos de sua formação, formam solos muito diferentes um do outro, desde as Areias Quartzosas atè solos podzolizados ou latossolos vermeIhos, com reaçōes peculiares a adição de fertilizantes.

Levando em conta a necessidade de contribuir para o melhor conhecimento desses solos, elaborou-se o presente trabalho, cujo objetivo precipuo foi estudar, atravess de ensaios de laboratörio, casa de vegetação é de campo, os efeitos da aplicação do micronutriente boro em milho e feijão.

Essas culturas foram escolhidas devido a sua grande importäncia na região.

Foram utilizadas duas unidades de solos sob cerrado, classificadas como Latossolo Vermel ho Amarelo fase arenosa e Regossolo que ocorrem no Municipio de São Simão, e em outras áreas do Estado de São Paulo, per fazendo $6 \%$ da superficie total deste ültimo, sendo necessärio ressaltar que a segunda entidade de solo apesar de contribuir com apenas $0,9 \%$ da superficie do Esta do, tem as suas maiores manchas concentradas no Municí pio de São Simão e regiões circunvizinhas. 


\section{REVISÃO DE LITERATURA}

São relativamente poucos os trabalhos sobre reaçäo à boro nos solos do Estado de São Paulo. Sabe-se que determinadas plantas teem apresentado deficiência de boro, tais como, hortaliças, algodoeiro, cafeeiro, citrus e eucaliptus.

BRASIL SOBRINHO (1965), CASAGRANDE (1978), ALCARDE (1969), CATAN I et alii (1970) realizaram estudos procurando determinar os teores de boro solúvel nos solos do Estado e selecionar os solos com prováveis deficiências do elemento.

ESPIRONELLO (1972) estudou a ração da cana de açücar a adição de Boro em solos do municipio de Piraci caba. Apesar de serem condiderados baixos os teores deboro encontrados não houve reação da cana à adição do boro.

CARVALHO (1981 b), em algodoeiro, encontrou boas reações à adição de boro em L.V.E., fase orto da região de Leme (SP).

CARVALHO (1981 a) encontrou reação no plantio de eucaliptos em solos, primitivamente, cobertos com vegetação de cerrado.

Assim, outras culturas também tem mostrado reações, como ocorre com o cafeeiro, batatinha, etc.. Havendo encontrado poucas informações quanto ao boro, iso ladamente no milho (Galrão E Mesquita Filho, 1981) e no feijoeiro (Machado et alii, 1979), (LOPES, 1984). Aliás este ültimo autor relata, de uma maneira geral, apenas em alguns casos respostas a adição de boro nos cerrados de Goìàs. 


\section{MATERIAL E METODO}

\section{Solos}

A ärea experimental utilizada pelos ensaios pertence à Estação Experimental de São Simão, do Ministério da Agricultura, Municipio de São Simão, Estado de São Paulo.

Os solos utilizados nos ensaios foram classifica dos por LEMOS et alii (1960), respectivamente, como Latossolo Vermelho Amarelo - fase arenosa e Regossolo (Areias Quartzosas). Acham-se localizados na região ocupa da pela referida Estação, situada numa altitude aproximada de $640 \mathrm{~m}$ e submetida a uma precipitação mëdia anua) de $1.424 \mathrm{~mm}$.

\section{Amostragem}

Depois de removida a vegetação natural, constituida de espécies típicas de "cerrado" que cobriam os solos pesquisados, foram coletados de cada unidade, para a realização dos testes de casa de vegetação cerca de $350 \mathrm{~kg}$ de terra do horizonte superficial a uma profundidade de 0 a $20 \mathrm{~cm}$. Ao mesmo tempo coletou-se, para fins de anälise química amostra composta da ärea.

Caracteristicas granulométricas e químicas dos solos.

As caracteristicas granulométricas dos solos expressos em percentagem de argila, areia total e limo fo ram determinadas pelo método de Bouyoucos (Bouyoucos, 1951) e se encontram na Tabela 1.

As anālises químicas foram efetuadas segundo CATANI et alii (1955) e VETTORI (1969) e os resultados encontram-se na Tabela 2. 
Tabela 1 - Caracteristicas granulométricas dos solos.

\begin{tabular}{lccc}
\hline Solos & \multicolumn{3}{c}{ TFSA } \\
& $\begin{array}{c}\text { Areia } \\
\text { Total } \\
\%\end{array}$ & Argila & Limo \\
& $\%$ & $\%$ & $\%$ \\
\hline L.V.A. fase arenosa & 46,5 & 47,5 & 6,0 \\
Areias Quartzosas & 79,7 & 16,3 & 4,0 \\
\hline
\end{tabular}

Determinação do boro solūvel dos solos.

o boro solúvel foi extraido pelo tratamento do solo com água fervente durante 5 minutos e determinado pelo método da curcumina segundo a téenica de Dible et ali $i$, citado por DEL RIO \& BORNEMISZA (1961) e modif $\overline{i-}$ cada por CATANI et alii (1970), que substituiu a solução de $\mathrm{CaCl}_{2}$ pela de $\overline{\mathrm{HCl}} 0,1 \mathrm{~N}$ como floculante do coloi de.

Os teores de boro encontrados foram de 0,16 ppm no LVA e de 0,36 ppm nas Areias Quartzosas.

Determinação do boro solūvel em $\mathrm{HCl} 6 \mathrm{~N}$ do corretivo

Foi fei ta tambēm a determinação do boro solūvel em $\mathrm{HCl}+6 \mathrm{~N}$ do calcário usado nas experiências de campo. 0 método utilizado nessa determinação foi o da curcumina, segundo DIBLE, BERGER \& TRUOG (1954).

A preparação do extrato foi feita de acordo com - que descreve VALADARES et alii (1974).

Uma grama de amostra moida do material foi umedecida com água desionizada e tratada com $10 \mathrm{ml}$ de uma solução de $\mathrm{HCl}$ destilado $\pm 6 \mathrm{~N}$ 


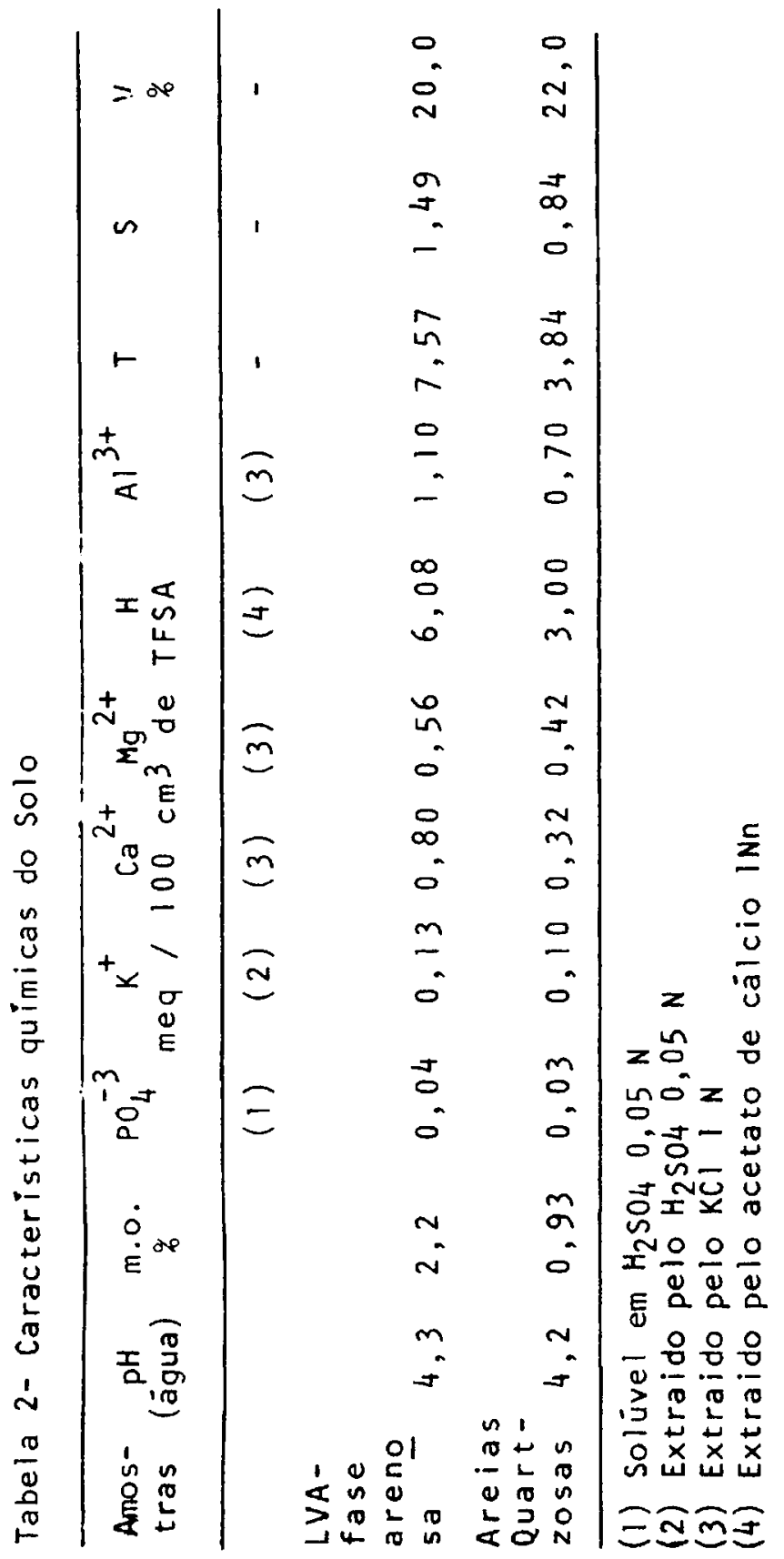


Anais da E.S.A. "Luiz de Queiroz"

Após 12 horas de contato, levou-se em banho Maria até a secura completa, sendo o residuo retomado com $20 \mathrm{ml}$ de $\mathrm{HCl} 0,1 \mathrm{~N}$. Agitourse e tomou-se $1 \mathrm{ml}$ do extrato para a determinação, pelo método da curcumina. As anälises foram feitas com duas repetições.

foi de $10 \mathrm{ppm}$.

o teor de boro solúvel determinado no calcário

Testes de boro com girassol (Helianthus annus L.) em casa de vegetação.

Coleçãó de padrões

Foram conduzidos dois ensaios, tendo como substra to areia de quartzo. Esses ensaios foram realizados em vasos de $500 \mathrm{ml}$ de capacidade, pintados inteiramente, com uma tinta betuminosa vendida no comércio com o nome de Neutrol $45\left(^{*}\right)$ contendo cada vaso $500 \mathrm{~g}$ de areia de quartzo.

A finalidade desses ensaios foi a de testar entre duas variedades de girassol, a Guaycan (semente riscada) e a Peohem-semente preta, qual a que apresenta melhores condições como planta teste na coleção de padrões de boro.

A técnica empregada na execução desses ensaios foi a mesma utilizada por BRASIL SOBRINHO (1965) e por ESPIRONELLO (1972).

A areia de quartzo usada como substrato nesses ensaios foi previamente lavada com āgua de torneira, so lução de $\mathrm{HCl}$ a $10 \%$ durante 48 horas, e, finalmente, com ägua destilada, até a eliminação de todo o ion $\mathrm{Cl}^{-}$proveniente da ägua de torneira.

(*) Neutrol 45 - tinta betuminosa fabricada por otto Baungart, São Paulo, Estado de São Paulo. 
Como fonte de nutrientes, para o teste do Girass..1, foi usada uma solução nutritiva de Colwell, ci tado por BRASIL SOBRINHO (1965) a qual continha todos os elementos essenciais ao desenvolvimento do girassol, com excessão do boro que foi adicionado em doses crescentes conforme demonstra a Tabela 3 .

0 esquema experimental usado nos dois testes foi - de blocos inteiramente casualizados em 7 tratamentos e 4 repetições.

O plantio do Girassol (variedade Peohēn) foi fei to em março de 1973 tendo se colocado 10 sementes em cā da vaso. 0 desbaste por vaso foi efetuado aos 9 dias após a germinação, deixando-se 5 plantas por vaso.

A solução nutritiva foi fornecida em dias alterna dos a partir do desbaste, na quantidade de $10 \mathrm{ml}$ até aos 14 dias apōs a emergência das plantas. Daí até a co lheita, que se deu em maio de 1973, foram acrescidas mais $15 \mathrm{ml}$ perfazendo um total de $25 \mathrm{ml}$, tambëm forneci da em dias alternados.

Procurou-se manter um teor de āgua adequado nos vasos, o suficiente para evitar a eventual perda de tur gidez de uma ou outra planta de cada vaso, utilizandose sempre àgua destilada nas irrigações.

Tres foram os tipos de mensurações utilizadas (BRASIL SOBRINHO, 1965): Valor-idade, altura das plantas em cm e peso da matéria seca em gramas. As duas culturas foram efetuadas aos 70 dias, por ocasião da colhei ta dos ensaios.

o valor-idade (nümero de dias que levava para o aparecimento de sintomas de deficiência de boro em relação à data da emergência) era avaliada quando os sintomas atingiam a primeira planta do vaso. Esses sintomas eram confirmados numa 2 ? fase, com a morte da gema ter- 


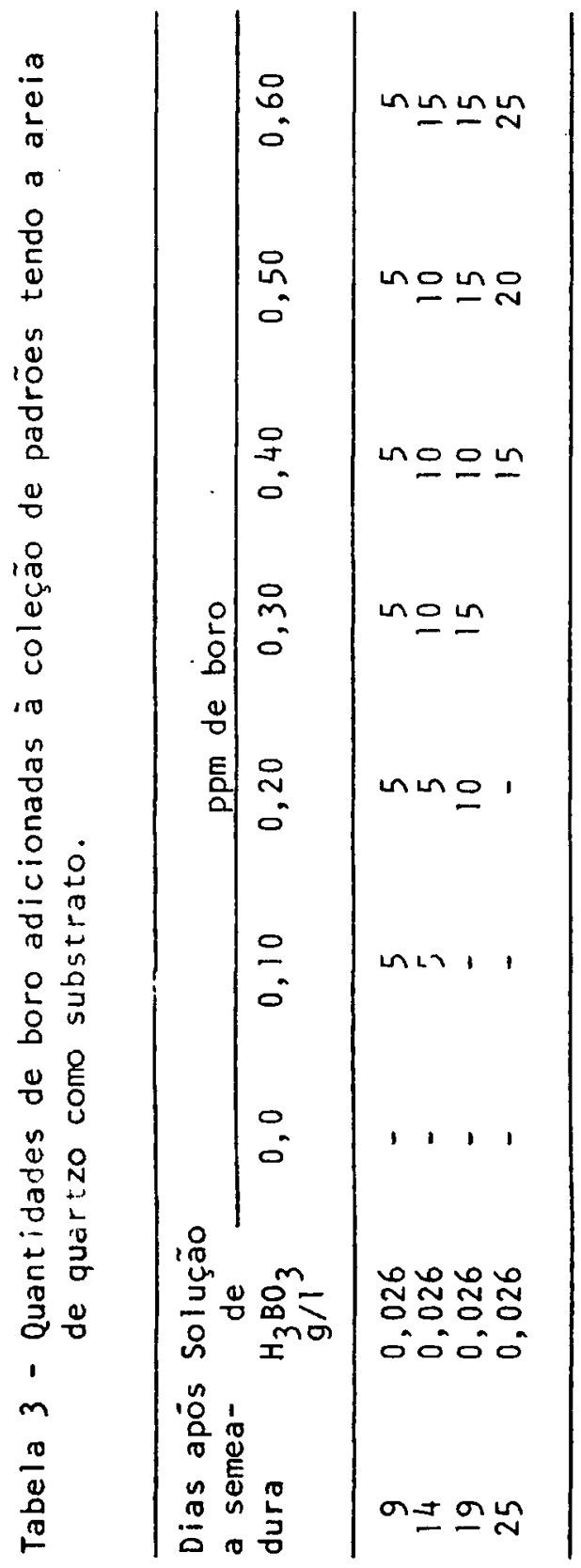


minal da planta.

Testes com solos

Nos testes com os solos houve a necessidade de se fazer a correção de acidez das mesmas, utilizandose $0 \mathrm{CaCO}_{3}$ p.a. na base de $4 \mathrm{t} / \mathrm{ha}$, para o LVA e de $2 \mathrm{t} / \mathrm{ha}$ para as Areias Quartzosas.

A variedade de girassol usada foi a "Peohen" e todas as unidades e tēcnicas foram as mesmas das utilizadas nos padröes. Os solos não receberam o boro.

Ensaios de aplicação de boro no feijoeiro (Phaseolus vulgaris L.) em condiçōes de campo.

A: äreas do ensaio de campo foram as mesmas de onde se fez a amostragem na Estação Experimental de São Simão, do Ministērio da Agricultura. Os tratamentos, em nümero de seis, representavam $0,1,0,2,0,3,0,4,0$ e $5,0 \mathrm{~kg}$ de $B /$ ha sob a forma de borax $(10,1 \%$ de B). 0 en saio tinha 4 repetições, distribuidas em blocos ao acaso.

Os solos receberam a calagem, 3 meses previamente ao plantio, respectivamente, de $4 \mathrm{t} /$ ha para o LVA $e$ de $2 t$ /ha para a Areias Quartzosas. No dia do plantio, foi coletada amostra dos solos e analisadas na sua necessidade de calagem e em boro para se avaliar o compor tamento da calagem e se o teor de boro havia se altera= do.

Após essa 2\% anāl ise, constatou-se que os valores $V$ haviam passado Dara $33 \%$ e $38 \%$, respectivamente, para o LVA e areias quartzosas. 0 teor de boro, após a calagem, havia crescido de 0,16 ppm para 0,38 no LVA e de 0,36 para 0,44 nas Areias Quartzosas. Nota-se que houve um enriquecimento de boro no LVA e nas Areias Quar tzosas pode ter havido, tambëm, perda por lixiviaçāo. 
A adubação do feijoeiro foi feita com 40, 100 e $30 \mathrm{~kg} /$ ha de $\mathrm{N}, \mathrm{P}_{2} \mathrm{O}_{5}$ e $\mathrm{K}_{2} \mathrm{O}$, respectivamente; nas formas de sulfato de amonio, superfosfato simples e cloreto de potássio, acrescidos dos demais micros.

O nitrogênio foi aplicado todo em cobertura, metade 8 dias após a emergência e metade 10 dias após a 1? aplicação.

As parcelas tinham $7 \times 4 \mathrm{~m}$ e oito linhas deixando-se duas bordaduras.

O feijão era da variedade "Carioca" e foi semeado à razão de très sementes por cova, a cada $20 \mathrm{~cm}$ dentro das linhas, deixando-se 2 plantas por cova.

Anälise Estatistica

Foram feitas as anālises estatísticas segundo PIMENTEL GOMES (1966).

\section{RESULTADO E DISCUSSÃO}

Boro solúvel nos solos.

As anālises de boro solūvel em ägua fervente revelaram $0,36 \mathrm{ppm}$ para a Areias Quartzosas e de $0,16 \mathrm{ppm}$ para o LVA. Em se tratando de solos acidos e de reconhe cida baixa fertilidade, provenientes de vegetação de cerrado,esses vajores parecem altos em relação aos dados de BRASIL SOBRINHO (1965). Entretanto, como os solos ha viam sido desmatados na época dos ensaios é provável que a presença maior de matéria orgânica proveniente não só do solo mas também de detritos vegetais possam ter modificado os teores. 
0 mesmo argumento pode ser usado na $2 \%$ anālise frita 3 meses após a calagem e que revelou um acréscimo de mais de $100 \%$ para o LVA $(0,38 \mathrm{ppm})$. Deve-se acrescen tar o boro contido no calcário (10 ppm ou $1 \mathrm{~g} / \mathrm{t}$ ) que calculado para as doses aplicadas corresponderia a $40 \mathrm{~g} / \mathrm{ha}$.

Para as areias quartzosas, mais sujeitas a $1 \mathrm{i} \times \mathrm{i}-$ viação, o teor de boro subiu de 0,36 para $0,44 \mathrm{ppm}$.

Ensaios de Boro em casa de vegetação com girassol

$0=$ resultados do ensaio de girassol representados como altura em $\mathrm{cm}$, valor-idade e o peso em gramas se en contram na Tabela 4.

Em primeiro lugar, levando-se em conta a altura em $\mathrm{cm}$ (Tabela 4) das plantas observa-se que para os padrões houve diferenças significativas pelos testes $F$ e de Tukey a 5\%. Assim, o tratamento 0,20 è maior do que o 0,10 e o 0 e o 0,60 é maior do que o 0,5 ppm; 0,30 , 0,40 e 0,50 são iguais. A anālise de variancia mostrou que a regressão linear e a quadrática foram significati vas, optando-se pelo uso da quadrática. Nas Figuras $1 \bar{e}$ 2 pode se ver a posição dos 2 solos em relação a curva padrão. Segundo a classificação obtida por Colwell (FRAN CO, 1955) e obtida por BRASIL SOBRINHO \& FREIRE (1980) os niveis de deficiência se acham abaixo de 0,10 ppm; entre 0,10 e $0,30 \mathrm{ppm}$ se acha uma faixa de teores médios que podem ser deficientes ou não e acima de $0,30 \mathrm{ppm}$ teo res altos e provavelmente, não deficientes. Entre $34,40^{-}$ e $54,97 \mathrm{~cm}$ ou entre 2,86 e 4,84 gramas de matéria seca acha a faixa média onde entra o LVA - fase arenosa. As areias quartzosas (Fig. 2) se colocam como teor alto $(67,7 \mathrm{~cm}$ e 6,3 de matéria seca) e provavelmente, não de ficientes em boro.

Os dados de crescimento estão de acordo com as análises químicas, sendo as Areias Quartzosas mais altas em boro do que o LVA. Os teores químicos encontrados pa- 


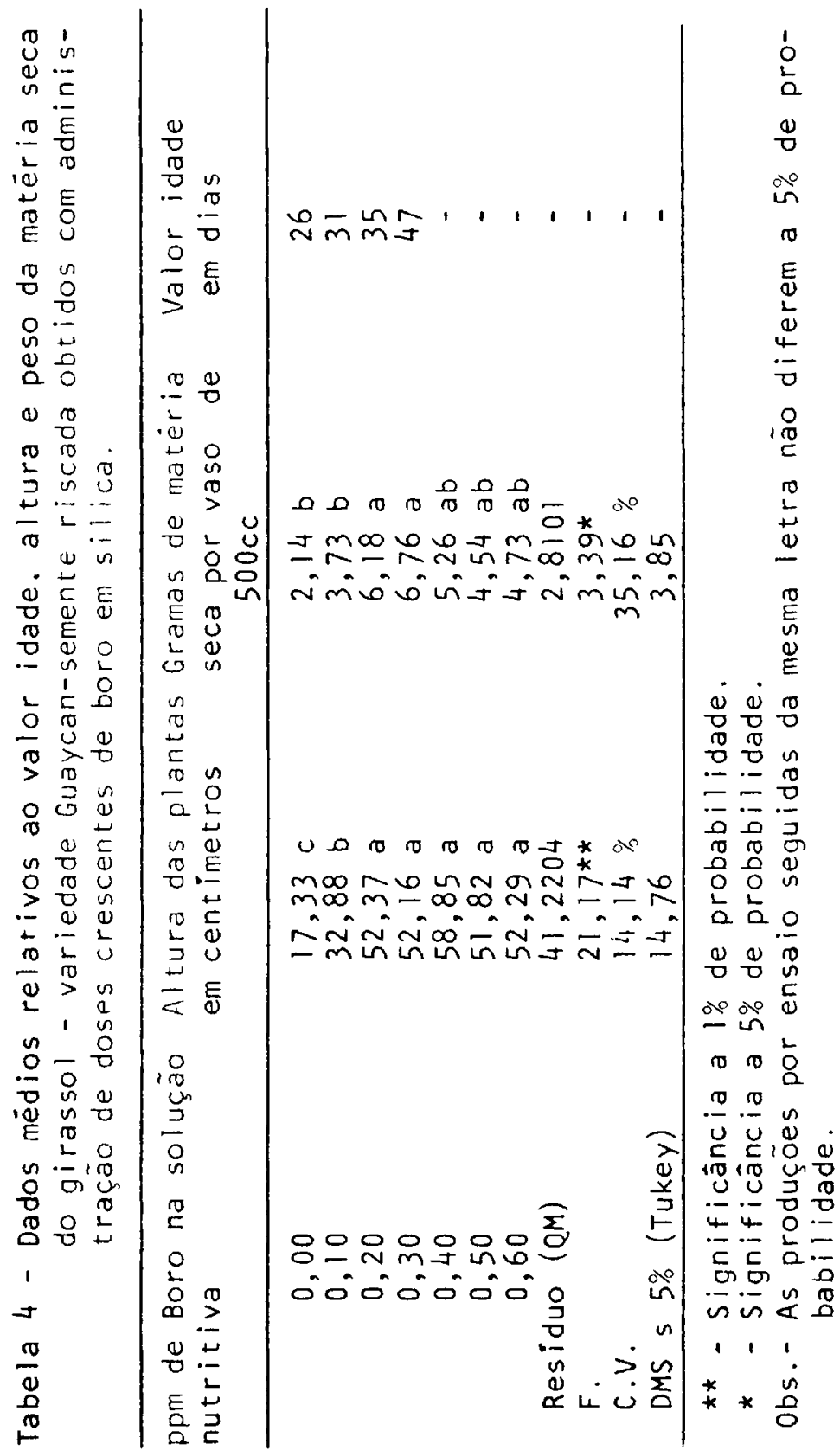




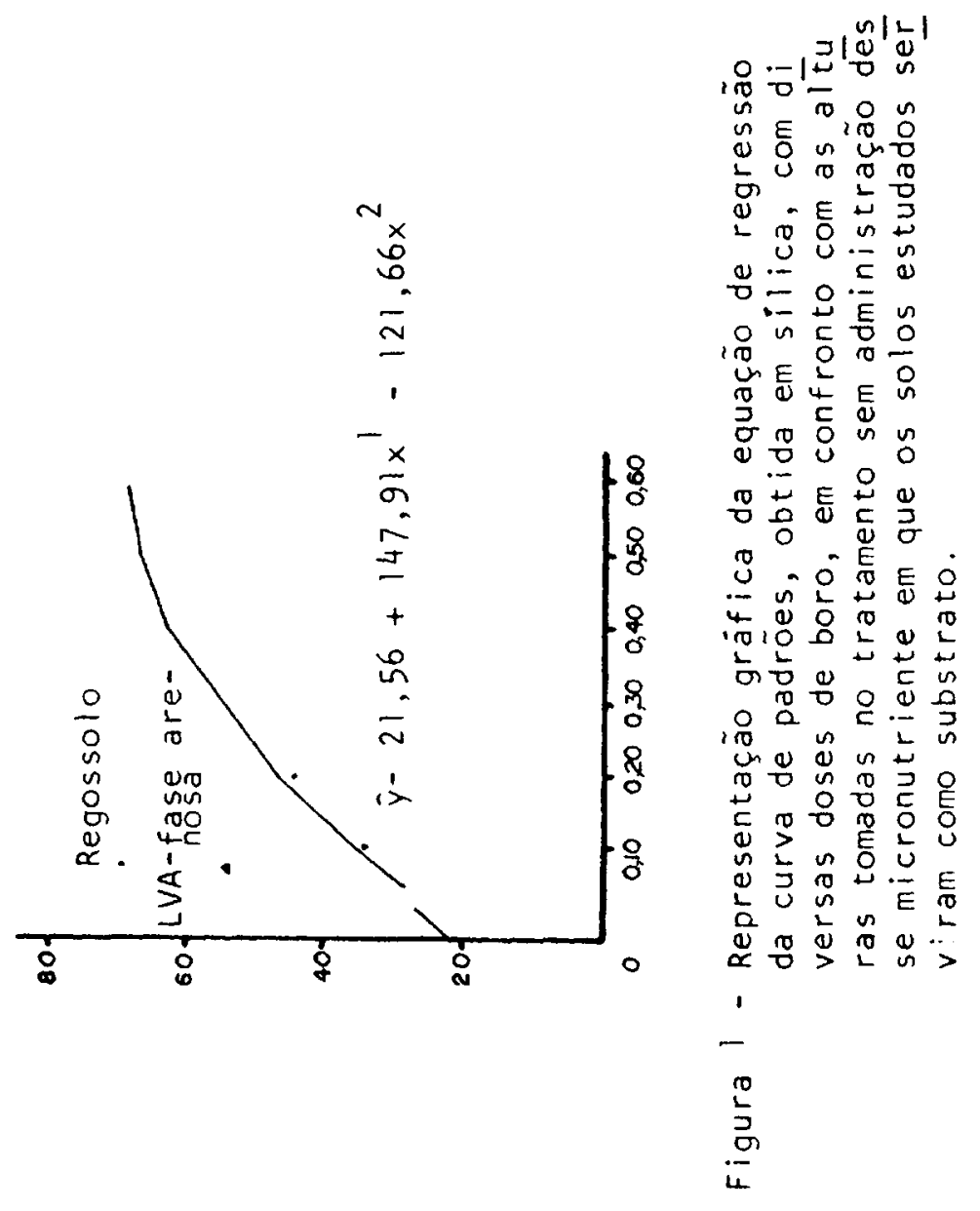




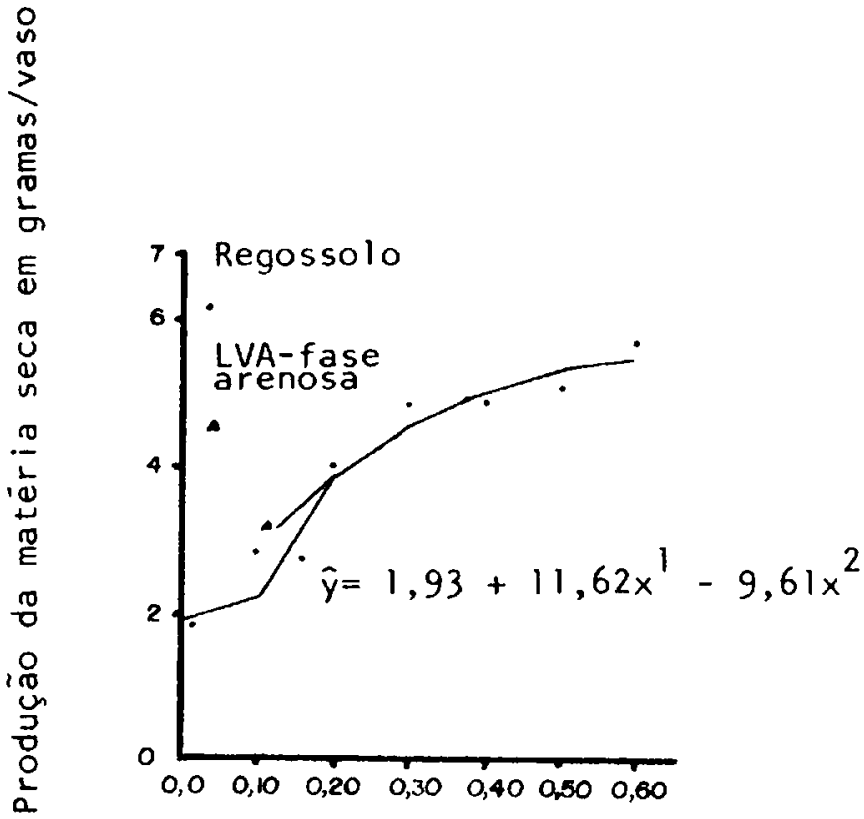

Figura 2 - Representação grāfica da equação de regressão da curva de padróes obtida em sílica, com doses crescentes de boro, em confronto com os pesos de matéria seca do tratamento sem administração desse micronutriente, em que os solos pesquisados serviram como substrato. 
ra as areias quartzosas tambēm foram mais al tos do que - esperado mas pode ter sido efeito do desbravamento recente do solo devido a presença de matéria orgânica no Ap ou pelo efeito deste fator mais a calagem, resultando em maior liberação de boro.

Pelos dados de valor-idade chega-se as mesmas conclusóes. 0 LVA apresentou 34 dias e a areia quartzosa 36 dias, na faixa de teores medios de boro, podendo ou não ser deficientes. Colwell, autor do processo, coIhia as plantas em torno de $42-45$ dias porque os valores-idades superiores a 35 dias para a variedade que usou, já refletiam solos não deficientes. Por outro lado, após os quarenta dias as deficiēncias de boro se con fundem com os sintomas do aparecimento da inflorescência que provoca tambèm a clorose das folhas terminais.

Por essa razão, é recomendável o uso da aplicação da coleção de padrões sobre o prōprio solo problema, pois, a adição de boro em doses crescentes seria a contraprova. Por outro lado tem havido nos ültimos anos muita troca de variedades de girassol no mercado. Se se desejasse repetir o trabalho de BRASIL SOBRINHO (1965) näo seria possivel pois a variedade utilizada era de porte gigante e bastante sensivel a boro. As atualmente espalhadas no mercado são talvez mais produtivas mas de porte vegetativo menor. O processo do girassol é muito bom mas é necessärio uma maior calibração da variedade empregada aliada tambēm as doses dos nutrientes fornecidos, que garantam a planta um pleno desenvolvimento na areia lavada.

Ensaios de aplicação de boro no feijoeiro em condiçöes de campo.

Os dados médios da produção de feijão em kg/parce la de $15 \mathrm{~m}^{2}$ da área util, e kg/hectare se acham na Tabe1 a 5 . 


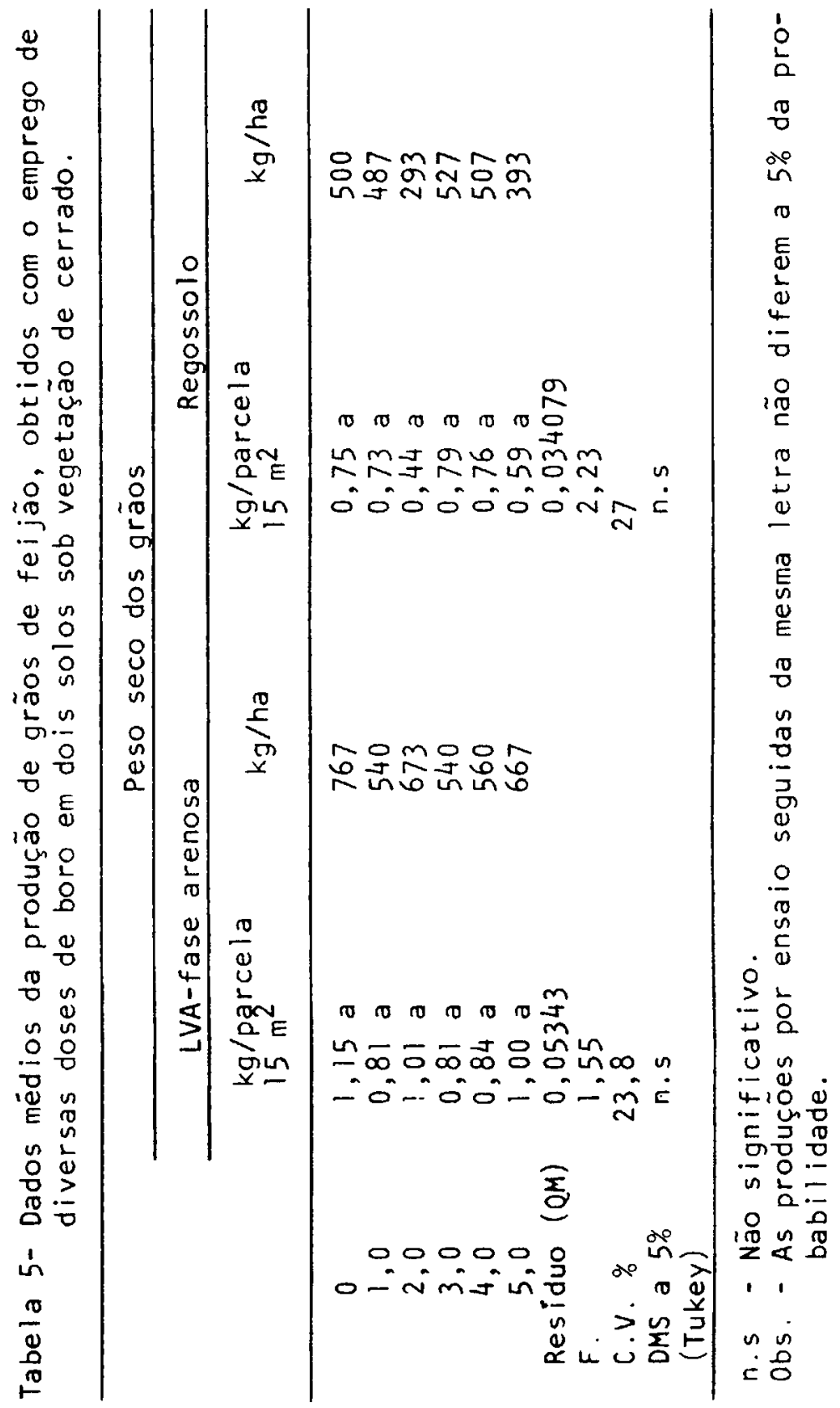


Pelo exame da Tabela nota-se que a anālise de variância nāo revelou diferenças significativas entre os tratamentos pelo teste $F$ e nem mesmo tendéncia de aumento com a aplicação de boro.

Se se analisar os dados químicos de boro encontrados nos solos após a calagem, os dados de girassol nis solos que receberam a calagem como $\mathrm{CaCO}_{3}$ puro e ns dados de feijão no solo,vê-se que os resultados se engrenam. Alia-se ao problema o fato de o feijão não ser muito sensivel a boro (BERGER, 1949).

CONCLUSÕES

- O teste biológico do girassol apresentou boa concordância com os dados analíticos indicando que as duas unidades de solo estudadas são ligeiramente defici entes ou não deficientes em boro.

- O solo classificado como Areias Quartzosas mos trou-se mais elevado em boro do que o Latossolo Verme-Tho Amarelo - fase arenosa.

- Não houve efeito da aplicação de boro na produção do feijoeiro.

SUMMARY

THE EFFECT OF THE APPLICATION OF BORON

IN SOILS OF THE "CERRADO" VEGETATION.

The present was carried out with the objective of studying the effects of boron applications on Red 
Anais da E.S.A. "Luiz de Queiroz"

Yellow Latosol - sandy phase and on Regossol (Quartzosas Sand) under "Cerrado" vegetation of São Simão, São Paulo, State.

Chemical determinations of soluble boron were ma de on soil samples of the experimental area collected before and after dolomitic line applications.

Complementary biological tests of boron were also made, employing sunflower (Helianthus annus L.).

Simultaneously, fold experiment was carried and with dry (Phaseolus vulgaris L.) to study boron applications.

The main conclusions were the followings:

I- Biologycal tests with sumflower were correlated with chemical analysis indicating that both soil units were slightly or no boron deficient.

2- The soil classified how Regosol (Quartzous Sand) showed a larger Boron content than the Red Yellow Latosol-sandy phase.

3- There has been no response of dry beans to boron on both soils.

\section{LITERATURA CITADA}

ALCARDE, J.C., 1969. A determinação do Boro pelo método colorimétrico da curcumina. Tese apresentada a E.S.

A. "Luiz de Queiroz" para obtenção do título de Doutor em Agronomia, Piracicaba (SP), $78 \mathrm{p}$.

BERGER, K.C., 1949. Boron in Soil and Crops. In Advances in Agronomy 1: $321-351$ 
BOUYOUCOS, G.J., 1951. A Recalibration of the Hydrometer Method for making Mechanical Analysis of Soils. Agronomy Journal 45(9): 434-439.

BRASIL SOBRo, M.O.C., 1965. Levantamento do teor de boro em alguns solos do Estado de São Paulo. Tese apre sentada a E.S.A. "Luiz de Queiroz" para obtenção do titulo de Livre Docente de Quimica Agricola. Piracıcaba, SP. 135 p.

BRASIL SOBRo \& FREIRE, 0.. 1980a. Boro en alguns solos do Estado de São Paulo - Avaliação por métodos quími cos. Revista da Agricultura, 55:83-105.

BRASIL SOBRo E FREIRE, 0., 1980b. Boro em alguns solos do Estado de São Paulo. Avaliação por métodos biológicos. Revista da Agricultura, 55:115-126.

C.RVALHO, L.H., 198la. Efeitos da calagem e da adubação boratada sobre algodoeiro (Gossippium hersutum L.) cul tivado em Latossolo Vermelho Amarelo - fase areno sa. Dissertação apresentada a ESAL.Q, para obtenção do grau de Mestre em Solos e Nutrição de Plantas, pu blicada pela Fundação Cargill, 1981.

CARVALHO, C. MARCHESI, 1981b. Efeitos da adubação com micronutrientes e Boro no desenvolvimento e no equilibrio nutricional do Eucalyptus saligna smith. Tese apresentada á ESALQ para a obtençao do grau de Doutor em Solos e Nutrição de Plantas, 1981.

CASAGRANDE, L.C., 1978. O Boro em solos do municipio de Piracicaba. Dissertação de Mestrado apresentada á E.S.A. "Luiz de Queiroz", en Solos e Nutrição de Plan tas, Piracicaba, SP.

CATANI, R.A., GALLO, J.R. \& GARGANTINI, H. 1955. Amostragem de solo, métodos de análises, interpretação e indicações gerais para fins de fertilidade. Bol. 
Anais da E.S.A. "Luiz de Queiroz"

69, Instituto Agronômico de Campinas, $29 \mathrm{p}$.

CATANI, R.A., ALCARDE, J.C. e KROLL, M.F. 1970. Extração e determinação do boro solüvel dos solos. Anais da E.S.A. "Luiz de Queiroz", Piracicaba (SP), 27:287294.

DIBLE, W.T., BERGER, K.C. e TRUOG, E. 1954. Boron determination in Soils Plants. Simplifled Curcumine Procedure. An. Chem. 26(2):418-421.

DEL RIO, J.F.S. e BORNEMISZA, E.S. 1961. Analisis químico de suélos. Métodos de laboratório para diagnosis de fertilidade. Departamento de Energia Nuclear, Ins tituto Interamericano de Ciências Agrícolas de la OEA, Turrialba, Costa Rica.

ESPIRONELLO, A., 1972. Estudos sobre Efeitos do Boro na Cana-de-açúcar (Saccharum spp) cultivada em alguns so los do Municipio de Piracicaba. Tese de Doutoramentoapresentada à E.S.A. "Luiz de Queiroz", da USP, Piracicaba (SP), $58 \mathrm{p}$.

FRANCO, A.B., 1957. Determinaciōn biológica de Boro em ocho suelos del valle del Cauca, Acta Agronomica VII (2) : $104-139$.

LEMOS, R.C. et alli. 1960. Levantamento de Reconhecimento dos SoTos do Estado de São Paulo. Boletim de Servi ço Nacional de Pesquisas Agronômicas, n? 12, Ministerio da Agricultura.

LOPES, A.S., 1984. Uso eficiente de fertilizantes com mi cronutrientes. In: Anais do Simpósio sobre fertilizañ tes na Agriculturra Brasileira. EMBRAPA, ANDA, POTAFŌ $\bar{S}$ Brasilia, 1984. 347-382.

PIMENTEL GOMES, F., 1966. Curso de Estatistica Experimen tal, ESALQ. Piracicaba, 30 edição, 1966. 404 p. 
VALADARES, J.M.A.S., BATAGLIA, D.C. E FURLANI, P.R., 1974. Estudo de materiais calcarios usados como corretivos do solo no Estado de São Paulo. III - Determinaçäo do Mo, $\mathrm{Co}, \mathrm{Cu}, \mathrm{Fe}, \mathrm{Mn}$ e $\mathrm{Zn}$. Anais do XIV Con gresso Brasileiro de Ciência do Solo. p. 378-379 (Resumo)

VETTORI, L., 1969. Métodos de Anälise de Solo. Boletim Técnico n? 7. Equipe de Pedologia e Fertilidade do Solo. EPE. Ministério da Agricultura. $24 \mathrm{pp}$. 